\section{CONOCER ES ACTUAR. ENTRE LA EPISTEMO-
LOGIAA GENÉTICA Y EL LEGADO DE PAULO \\ CONOCER ES ACTUAR. ENTRE LA EPISTEMO-
LOGIA GENÉTICA Y EL LEGADO DE PAULO FREIRE}

KNOWING IS ACTING. BETWEEN GENETIC EPISTEMOLOGY AND PAULO FREIRE'S LEGACY

\author{
Jorge A. González \\ CEIICH-UNAM (México) \\ ORCID: 0000-0001-7844-9260 \\ jorge.labcomplex@gmail.com
}

Para citar este artículo:

González, J. A. (2020). Conocer es actuar. Entre la epistemología genética y el legado de Paulo Freire. Commons. Revista de Comunicación y Ciudadanía Digital, 9(2), 79-103. http://doi.org/10.25267/COMMONS.2020.v9.i2.02

Fecha de recepción: 03/06/2020. Fecha de aceptación: 31/08/2020

\section{Resumen}

La clave de la construcción del conocimiento tiene que ver con empoderar a las personas. Especialmente aquellos que han sido "diseñados" y tratados como meros objetos de estudio y no como sujetos activos de conocimiento. Ese es uno de los resultados más importantes del legado de Paulo Freire, no solo en Brasil, sino en el mundo. Pero, ¿qué significa convertirse en "sujetos de conocimiento"? Los actores sociales que pueden enfrentar sus problemas mediante la construcción de su propio conocimiento, ¿realmente se empoderan? La teoría y los hallazgos otorgados desde la Epistemología Genética nos brindan una poderosa herramienta teórica y metodológica para comprender las experiencias de "concientización" como procesos de empoderamiento. El método de Freire para la alfabetización puede interpretarse fructíferamente a la luz de una teoría científica de los procesos de construcción del conocimiento. Al estudiar y practicar la Comunicación para el Desarrollo, afirmo que la Información, la Comunicación y el Conocimiento deben ser considerados como un proceso crucial triple, no separable, que incluye simultáneamente transformaciones biológicas, conductuales y sociales, especialmente aquellas que han sido creadas colectivamente. Estas transformaciones mejoran la capacidad tanto individual como grupal para diferenciar e integrar (es decir, "conocer") sus experiencias del mundo, y al hacerlo, empoderan su capacidad de actuar, confrontar y superar sus condiciones sociales.

\section{Palabras clave}

Epistemología Genética, pedagogía del oprimido, conocimiento

\begin{abstract}
The key of knowledge construction has to do with empowering people. Especially those who have been "designed" and treated as merely objects of study and not as active subjects of knowledge. That is one of the most important outcomes of Paulo Freire's legacy, not only in Brazil, but in the world. But, what does it mean to become "subjects of knowledge"? The social actors who can confront their problems by mean of the construction of their own knowledge, do they really become empowered? The theory and findings granted from Genetic Epistemology, gives us a powerful theoretical and methodological tool for understanding the experiences of "conscientization" as processes of empowering. Freirean method for literacy can be fruitfully interpreted under the light of a scientific theory of the processes of knowledge construction. In studying and practicing Communication for Development, I claim that Information, Communication and Knowledge must be taken as a crucial threefold, non-separable process that includes simultaneously biological, behavioural and social transformations, especially those that have been collectively created. These transformations improve both, individual and group capacity to differentiate and integrate (that means, "knowing") their experiences of the world, and by doing that, empower their capacity of acting, confronting and overcome their social conditions.
\end{abstract}

\section{Keywords}

Genetic epistemology, pedagogy of the oppressed, knowledge 


\section{Introducción ${ }^{1}$}

En este breve texto, me propongo dos objetivos. El primero, iniciar y sugerir un diálogo conceptual entre el legado de Paulo Freire y algunos de los fundamentos de la Epistemología Genética, la disciplina científica que Jean Piaget y sus colaboradores, entre quienes destaca Rolando García, crean y desarrollan intensa y profusamente durante la segunda mitad del siglo pasado para estudiar los procesos de construcción del conocimiento en la especie humana.

El segundo objetivo estará centrado en mostrar que ambas tradiciones y perspectivas, no solo no se contraponen ni compiten entre sí, sino que se complementan y potencian mutuamente dentro del espacio controversial de la así llamada comunicación para el desarrollo. Al cierre de esta segunda parte presentaré algunas bases de nuestra perspectiva sobre la construcción y desarrollo del conocimiento dentro de un área de exploración y conceptualización que quiere ir un poco más allá de los límites dentro de los que fue fundada y consolidada la Epistemología Genética: los procesos psicogenéticos y la historia de la ciencia, usada como laboratorio epistemológico por Rolando García (Piaget \& García, 1982).

Dedicaré un poco más de espacio a la exposición de esta epistemología científica, en parte porque este texto anticipa un lector probablemente no familiarizado con ella y también por el efecto de la visibilización reducida e instrumentalizada que prevalece sobre la profusa obra de Piaget y de Rolando García. El texto cierra con un breve apunte de una perspectiva heredera de ambas perspectivas que he llamado cibercultur@ (González, 2019). El núcleo de ella apunta a la investigación y el desarrollo de las relaciones que la información, la comunicación y el conocimiento juegan en el ejercicio de la función simbólica de las sociedades humanas para así conocer/actuar sobre los problemas de la vida en sociedad.

1. La producción y escritura de este artículo fue posible gracias al apoyo del PASPA-DGAPA-UNAM. 


\section{Trenes paralelos: dos perspectivas, dos autores, dos propósitos}

Freire y Piaget son dos de los autores más recurridos y citados en los ámbitos de la pedagogía, la educación, la psicología, la enseñanza y hasta de los movimientos sociales (Caldart, 2004). Estos dos autores suelen ser vistos y, en el mejor de los casos, leídos como parte de diversos cursos universitarios. De hecho, en nuestra formación en el área de comunicación, desde el primer semestre de la carrera nos encontramos leyendo a ambos autores (González, 2018: 282). La lectura de Freire (1973) nos conmovió emocionalmente; mientras que la de Piaget (1973), aunque nos parecía fascinante, no logramos entenderla sino muchos años después gracias al trabajo conjunto con Rolando García. Entender, siempre depende de la estructura del que entiende, no solo del contenido a entender.

\section{Freire: alfabetizar para la libertad}

Por un lado, Freire deja muy claro que su pedagogía del oprimido no es solamente un método de aprendizaje instrumental de las letras, sino una forma de praxis social cuyo fin inmediato es la habilitación de la capacidad para leer y escribir más allá de las letras y los textos, es decir, una práctica para "leer" y "escribir" (acción transformadora) en ese mundo (Freire, 1973; Freire, 1993).

El objetivo no es solo "alfabetizar", sino directamente, concientizar. Es pues, una forma de intervención consciente y deliberada dentro de la organización desigual de la sociedad que se ha convertido en ignorancia, autodesprecio fatalista e incapacidad de organización colectiva para cambiar las relaciones que hacen que el mundo de los analfabetos sea de esa forma y no de otra. Con ello, busca la transformación de esa situación y miserable condición de millones de hombres y mujeres que, la historia de las desigualdades objetivada en cada lugar, en cada poblado, en cada favela, en cada agroindustria, en cada fábrica, ha establecido en el curso de la historia. Es la pobreza la que está detrás de lo inaccesible de la lectoescritura - y no al revés, como suele pensarse (Dale \& Hyslop-Margison, 2010)—, es decir, no son pobres porque sean analfabetos, sino al revés. 
El método de Freire busca generar la apropiación individual y colectiva de ese poderoso artefacto cultural (Vygotski \& Luria, 2007) que les permitiría modificar su condición reflexiva y práctica, no solo como individuos sino también, y muy especialmente, como colectivo.

En el horizonte utópico de la propuesta de Freire está el hecho de que al liberarse como oprimidos también se libera al opresor:

La violencia de los opresores, deshumanizándolos también, no instaura otra vocación, aquella de ser menos. Como distorsión del ser más, el ser menos conduce a los oprimidos, tarde o temprano, a luchar contra quien los minimizó. Lucha que solo tiene sentido cuando los oprimidos, en la búsqueda por la recuperación de su humanidad, que deviene una forma de crearla, no se sienten idealistamente opresores de los opresores, ni se transforman, de hecho, en opresores de los opresores, sino en restauradores de la humanidad de ambos. Ahí radica la gran tarea humanista e histórica de los oprimidos: liberarse a sí mismos y liberar a los opresores. (Freire, 2005: 41)

En esta perspectiva, no es con una relación de odio y destrucción que se rompe con la opresión. Es con la construcción de la importancia del otro, del "prójimo como yo mismo" que se reconstruye virtuosamente una visión crítica del doloroso mundo de la explotación, de la violencia, del abuso y la injusticia, que nada tienen de "naturales". Esas condiciones son históricas y por ello son cambiables. Por eso el fondo de la propuesta pedagógica y política de Freire está fundada en la ética (Dussel, 1998), en la escucha y en la transformación de los que se involucran en esa lucha, concebida y deseada como una praxis política plenamente liberadora.

De manera práctica, con el tiempo la pedagogía del oprimido se transmuta también en la pedagogía de la esperanza, es decir, en la prefiguración de otro mundo y otras relaciones que también son posibles como principio que orienta las acciones cotidianas, aun y cuando el mundo y las relaciones sociales injustas sigan atrayendo la energía social hacia esa zona oscura, densa, pesada y profundamente injusta que es la explotación económica y la dominación política. 
El pobre es un des-energizado social, no por su propia "naturaleza", sino por la naturaleza de las relaciones sociales que escapan a su conciencia. Esas relaciones de explotación, de despojo de energía social que someten y rebajan a quienes Freire llama "oprimidos", también rebajan y deshumanizan al explotador.

Resulta también entendible la relación tan estrecha que se ha dado entre la pedagogía de Freire y la Teología de la Liberación: "El cuidado solamente surge cuando la existencia de alguien tiene importancia para mi" (Boff, 2014: 103), "si los demás están bien, yo estoy mejor" (Krohling-Peruzzo \& González, 2018: 205235). El amor al prójimo, entendido de esta forma, libera.

Por estas y otras razones, además de establecer un método para la alfabetización de adultos, la obra de Freire es también toda una filosofía moral, una reelaboración en código amoroso y plenamente político de las relaciones con la vida, con los otros y con el mundo.

De ahí la importancia de instrumentarlo como una pedagogía de la autonomía (Freire, 2010) que requiere de la formación de un tipo particular de docentes que tienen que prepararse para establecer ese proceso cotidianamente, en todas las actividades y ejercicio de su profesión.

Solo resta decir que los ataques y pronunciamientos en Brasil contra Freire y su método, que buscan "sacar" la política de las escuelas para desterrar el "adoctrinamiento ideológico" de la enseñanza de los niños y una gama de denostaciones y descalificaciones, en la coyuntura de crisis que ha vivido la sociedad brasileña bajo el actual gobierno de Bolsonaro, nos indica que aquellos poderes que lo impugnan y descalifican saben muy bien del potencial desafío del statu quo que comportan el pensamiento y la obra de Freire. Estamos bien conscientes de que hay muchísimo más que puede y debiera ser dicho sobre este autor y esta perspectiva, pero otros textos en esta obra lo tocarán con más detalle.

Pasemos ahora revista con algún grado de detalle a algunas características de la epistemología genética. 


\section{Epistemología genética y psicología genética}

Desde mediados del siglo pasado Jean Piaget, biólogo de formación, psicólogo "por necesidad" y epistemólogo por vocación, junto con un equipo multidisciplinario que funda en el Centro Internacional de Epistemología Genética en la Universidad de Ginebra, inicia la fundamentación conceptual y empírica de una nueva ciencia que llamaron Epistemología Genética. El adjetivo "genética" lo coloca Piaget para diferenciarla de la bien conocida epistemología, una rama de la filosofía especulativa que exploraba desde la antigüedad, por ejemplo, las preguntas sobre qué es y de dónde viene el conocimiento. Otros adjetivos le son aplicados a esta naciente disciplina que, a diferencia de la epistemología a secas, asume la obligación de someter a pruebas empíricas sus formulaciones acerca del conocimiento. Piaget modifica las preguntas especulativas por otras científicamente más productivas: ¿qué conocemos?, ¿cómo conocemos?

Y más aún, su búsqueda dará luces sobre otra pregunta no planteada antes: ¿cómo se pasa de una estructura de conocimiento menos diferenciante a otra más diferenciante?

Su epistemología es "genética", no por su relación con los genes y las cadenas de ADN y ARN. El adjetivo lo usa Piaget para destacar que lo que le interesa es conocer en detalle qué es lo que una "estructura" anterior le "hereda" a otra en el tiempo y cómo se efectúa esa transformación.

Piaget se concentró en el desarrollo y fundamentación conceptual de una disciplina experimental que tuviera un dominio, un objeto y un método propios, al mismo tiempo que elaboraba una teoría lógicamente coherente y empíricamente contrastable de los procesos de conocimiento.

Freire, por su parte, en otras condiciones sociales y de producción discursiva, el proyecto de alfabetización que creó y estableció inicialmente en el semiárido Nordeste de Brasil, tuvo desde el inicio un horizonte de acción transformadora sobre las inhumanas e injustas condiciones de vida de la población más pobre, de los oprimidos. 
En apariencia, no hay nada que ver entre estos dos autores.

Freire tiene un claro compromiso político y práctico, un horizonte de crítica y transformación posible de las condiciones de miseria que han generado la deshumanización y el analfabetismo de millones. Piaget, nacido y educado en la sociedad Suiza de habla francesa, se propone llenar un vacío, para él decisivo, en el horizonte de las ciencias: una teoría científica de los procesos del conocimiento. Para conseguirlo, tuvo que contraponerse a dos fuertes tradiciones filosóficas que ya se habían ocupado, aunque de forma especulativa, de ello: el innatismo y el empirismo (García, 2000: 45-47).

Al primero se opone porque postula que los conocimientos "surgen" o "emergen" de forma natural ("innata") en las personas; es decir, porque esa tradición considera que ya están incluidos dentro de nuestra naturaleza de forma independiente de la experiencia de lo real. La Epistemología Genética muestra que todo conocimiento es el producto de una acción constructiva e implica por ello, un sujeto activo. Nuestra especie solo puede conocer cuando actúa sobre las cosas del mundo. Sin acción sobre el mundo real, no hay conocimiento posible.

Al segundo y más robusto adversario, todas las formas de empirismo, lo impugna porque supone que "la realidad" existe fuera de nosotros y solo la conocemos a través de los sentidos. Y aquí la cosa se complica un poco, porque las características y propiedades que podemos registrar (con los sentidos) de los objetos, depende de esquemas de relaciones establecidas por el sujeto. El vector de conocimiento va de lo pensado a lo real y no al revés, como alguna vez también lo señalara Gastón Bachelard.

Y se "complica", porque esta construcción conceptual es contraintuitiva. No se libera fácilmente el hecho de que solo podemos "ver" empíricamente, lo que nos permiten las relaciones internas. Las propiedades que registramos con los sentidos dependen de las relaciones. 
Esas dos posturas filosóficas sobre el conocimiento y la ciencia, que son las más influyentes del mundo occidental, son rechazadas por Piaget, que logra demostrar empíricamente que las explicaciones y fundamentaciones que había elaborado el empirismo lógico sobre el conocimiento son muy influyentes y rigurosas, pero científicamente falsas.

El conocimiento se construye, no "entra" del exterior a partir de experiencias sensoriales, sino mediante reelaboraciones sucesivas ocasionadas por crisis de los esquemas de acción que enfrenta condiciones a las que no está adaptado y por eso mismo implican a un sujeto activo que produce su conocimiento en interacción con sus objetos mediante una gama de procesos de abstracción reflexiva que hacen posible la anticipación, las deducciones y el diseño de la planeación.

En el desarrollo del conocimiento, esta disciplina nos explica cómo es que se hace posible, que se construye literalmente, la posibilidad de "no solo buscar lo que es bueno, sino también se puede buscar el bien, no solo el éxito, sino la comprensión o la verdad" (Becker, 2017: 17). Esta capacidad del desarrollo de los humanos constituye un salto cualitativo en el diseño de mundos posibles, de la reelaboración narrativa de la propia memoria y en la definición crítica del presente, como veremos en la parte final. Es esta Epistemología Genética la que, al explicar los procesos que se reorganizan logra volver inteligible y le da un soporte riguroso y desmitificador al proceso de lo que Freire llama "concientización". Esta conclusión está detrás del adjetivo "constructivista" que también suele darse a la Epistemología piagetiana.

Asimismo, la Epistemología Genética muestra de forma impecable que esa interacción no se puede comprender sin una concepción dialéctica de todo el proceso constructivo, pues éste siempre se genera a través de equilibraciones y reequilibraciones sucesivas de las estructuras cognitivas en crisis mediante la operación de mecanismos de construcción en permanente movimiento. "Estructura" en la Epistemología Genética no es un sustantivo, sino un "verbo". No hay estructura sin historia, como no hay historia sin estructura, respondería Piaget a quienes le criticaban como "estructuralista". Solo podemos conocer mediante nuestra interacción con los objetos, nos convertimos en plenamente humanos, es 
decir, seres sociales, cuando en el curso del tiempo desarrollamos esa capacidad de abstracción reflexiva sobre nuestras propias coordinaciones, que no pertenecen al "objeto", no vienen de "afuera", ni tampoco se pueden observar de forma directa.

Es esta una concepción profundamente revolucionaria e inédita en el entendimiento científico de los procesos de conocimiento que puede tener repercusiones importantes y fundamentadas sobre los modos de enseñanza y aprendizaje de las ciencias y por supuesto que también puede servir de soporte teórico y práctico en los procesos de alfabetización, que extraviados en tratar con las carencias de los sujetos alfabetizables, podrían orientarse en "(...) ayudar al adulto a comprender el modo de funcionamiento de la escritura a partir de lo que él ya ha construido, a partir de su saber efectivo y no de su ignorancia" (Ferreiro, 2007: 206).

El programa de trabajo de Piaget dedicó décadas a estudiar las etapas iniciales de la construcción del conocimiento. Esto implicó protocolos detallados para trabajar con niños y niñas, desde recién nacidos - con sus propios hijos- hasta adolescentes capaces de generar abstracciones reflexivas complejas, porque mediante su acción de conocimiento las han construido al pasar por múltiples períodos de desequilibración y reequilibraciones.

Cuando los niños logran construir este tipo de abstracciones, su sistema cognoscitivo está listo y habilitado para la vida social adulta.

Asimismo, las inferencias y teorizaciones diversas que Piaget realizaba sobre los procesos de conocimiento implicaron también la invención de una psicología genética, diseñada para estudiar la psicogénesis de los conceptos y realizar contrastaciones empíricas de las conceptualizaciones de la epistemología genética. Sin ninguna práctica política conocida, la monumental obra científica de Piaget, tanto por la utilización del método histórico-crítico, como por su concepción dinámica de los procesos de construcción de los conocimientos, lo coloca, como también podríamos ubicar el trabajo de Freire, dentro de la tradición de la dialéctica de Hegel, Marx y Lenin. Piaget, como el mismo Karl Marx, tampoco era "marxista", pero su concepción y uso de la dialéctica está en el fondo de la parte más creativa e importante de su toda su teoría (García, 2008: 202). 
Sin embargo, toda esta epistemología científica (constructivista/dialéctica/ genética) que fue desde el principio el objetivo de todo el trabajo de Piaget, parece haber quedado sepultada mediante un mecanismo selectivo que ha marcado a Piaget bajo las etiquetas de "psicólogo de niños", "pedagogo", "educador", "método activo" y suele ignorarse su teoría reduciéndola a la identificación y superación de las infaustas "etapas de desarrollo".

Becker nos proporciona algunas razones de esto:

Nuestro sistema escolar está organizado por franjas de edad. Esto facilita la gestión de la escuela. Sucede que ese principio administrativo, el agrupamiento de los alumnos por edad, fue transformado en principio pedagógico. (...) la teoría de Piaget, cuando entró en la escuela, fue interpretada como una teoría de las etapas (stage), en lugar de ser vista como estados (stade) o estadios, metáfora preferida por mucho. Con esto, todo el proceso de equilibración o de abstracción reflexionante fue reducido a un proceso de maduración. En una palabra, anuló su novedad. Aquello que debería ser entendido como un período de desarrollo, determinado por una estructura de conjunto construida activamente por el sujeto, que perdura durante cierto tiempo - un estado, por lo tanto- fue interpretado como resultante de un proceso de maduración, es decir, predeterminado en el genoma. (Becker, 2017: 22-23) (Traducción propia)

La visibilidad de Piaget como creador de una disciplina científica (la EG) que estudia los procesos de construcción de conocimiento se desdibujó por debajo de su fama como "educador activo". Desde luego que uno de los campos en los que puede ayudar esta nueva teoría del conocimiento como acción es en la educación y la pedagogía, la psicología infantil del desarrollo y otras ramas de aplicación que poco a poco fueron derivando de los trabajos de Ginebra. Uno de ellos, por ejemplo, es la Inteligencia Artificial desarrollada por el matemático Seymour Papert cuando después de diez años de colaborar con Piaget, fue reclutado en el MIT en los Estados Unidos, donde creó el lenguaje de programación "Logo" y promovió el "construccionismo" en continuidad con su práctica en Ginebra. En la consolidación institucional, la teorización sobre los experimentos y la activación procedimental de ese objetivo a lo largo de los años, Piaget atrajo deliberadamente a una larga lista de destacados colegas: Ilya Prigogine (Químico), Benoit Mandelbrot (Matemático), Lucien Goldman (Sociólogo), Bärber Inhelder (Psicóloga), Pierre Greco (Lingüista), Léo Apostel (Filósofo) y al final de su vida productiva, Rolando 
García (Físico de la Atmósfera y Empirista Lógico) así como muchos otros que colaboraron con él en el desarrollo de su epistemología genética y las dos primeras versiones de su teoría de la equilibración de las estructuras cognitivas.

\section{El binomio virtuoso Piaget-García}

Como sucede en una buena cantidad de ocasiones en la historia de la ciencia, el encuentro de Piaget con Rolando García es tan fortuito como afortunado para ambos (González, 2018). Las relaciones entre el influyente Círculo de Viena y el grupo de Ginebra, por efecto del propio desarrollo de la EG, construido contra los supuestos del Empirismo Lógico, no eran las mejores. Piaget logra que Bertrand Russell visite el Centro Internacional de Epistemología Genética, donde le muestra las experiencias de laboratorio, en las que fundamenta su posición anti empirista. Sin embargo, el filósofo británico y uno de los creadores del empirismo lógico, le responde irónicamente, que ellos dos nunca podrán entenderse, dado que él (Russell) se ocupa de "La Ciencia" y Piaget de "cosas de niños". Fin de la historia. No hubo ni diálogo ni entendimiento.

Para esta nueva ciencia, todo empirismo configura un formidable obstáculo epistemológico.

Cuando hablamos del empirismo, esa perspectiva que en el fondo sostiene que el conocimiento depende de lo que nuestros sentidos reporten (... "-En este laboratorio, el único que siempre tiene la razón es el gato-" ...) estamos señalando no solo un posicionamiento filosófico (que Piaget demostró como empíricamente falso), sino que afirmamos la existencia y la durabilidad de toda una estructura de relaciones de dominación (por la fuerza de los sistemas de evaluación, contratación y permanencia en las instituciones especializadas, en las facultades y escuelas) y de valoración aceptados o impuestos, que definen en la práctica lo que es y no es la "ciencia", lo "científico", sus prácticas especializadas y, desde luego, a las propias asociaciones científicas. 
Como si no existiera una disciplina científica sobre los procesos de conocimiento, el empirismo en todas sus formas y manifestaciones sigue siendo utilizado en los cursos de formación de los científicos y la mayoría de los no científicos en el mundo "occidental".

Me refiero a que, como corriente filosófica sobre el conocimiento, continúa orientando las evaluaciones, la estructura y los contenidos de la producción de textos, las revistas, las editoriales, las asociaciones, los temarios de las asignaturas, las prácticas periodísticas y pedagógicas sobre el sentido y la enseñanza básica del discurso científico, la historia de los científicos y sus descubrimientos y por supuesto, la sacralización de un único y verdadero Método Científico (salido de una etapa de la historia de la física) que se convirtió en un canon. Cualquier disciplina que no se rija por ese método, es mera especulación, creencia y subjetividad y, a lo sumo, una forma más de "pseudo-ciencia" (Bunge, 1983: 54).

La Epistemología Genética nos muestra históricamente que no existe un único e infalible "método científico", sino diferentes formas de cientificidad (González, 2019: 71, en González \& Krohling-Peruzzo, 2019) y que la ciencia es una forma de conocimiento más, pero no es ni la única ni a veces tampoco resulta ser la más útil. Nos muestra que, en la metodología de investigación, antes que dedicarse a comprobar hipótesis, debemos estar preparados para esperar lo inesperado.

Diversas prenociones y vicios sobre la ciencia y el conocimiento científico se siguen enseñando y desafortunadamente son incorporados y defendidos a ultranza, de manera rígida y acrítica por profesores y estudiantes de todas las disciplinas, tengo que repetirlo, como si no existiera desde hace años una sólida teoría científica de los procesos de conocimiento.

Podemos comparar esta paradójica situación de ignorancia selectiva con tres ejemplos.

En la filosofía, seguir enseñando la lógica silogística como si no hubiera existido Bertrand Russel y su metalenguaje formal, que nos hace ver que toda la lógica aristotélica opera con una sola relación (incluído/no incluído). En la química, seguir entendiendo el por qué se queman las cosas con fuego, recurriendo a la teoría del flogisto de Stahl, como si no hubiera existido Lavoisier y su construcción 
del papel del oxígeno como comburente. En la comunicación, seguir enseñando solo la teoría hipodérmica de la comunicación, como si no hubieran existido Katz y Lazarsfeld y su teoría de la influencia personal y la comunicación en dos pasos, en fin, como si no hubiera existido Marx y su teoría de la plusvalía como falsación de la teoría de la ganancia de la economía clásica.

Una vez impuesto y aceptado el canon empirista, con ello, también se sacraliza el cuantitativismo (si el estudio no tiene cantidades expresables en "matemáticas", puede ser cualquier cosa, pero no es "científico"). El movimiento contrario, que es igualmente empirista, pero solo de polaridad diversa, abona la disputa en favor de lo que he llamado en otros textos el "melatismo" (a mí me late que eso se comporta así y no necesito números para comprenderlo) porque la acción humana es como la historia, irrepetible y no puede ser explicada ni cuantificada, sino solamente interpretada, comprendida. La Epistemología Genética nos enseña que comprender y explicar, son dos momentos complementarios y no polos opuestos en toda investigación.

Todavía muchas instituciones universitarias están internamente escindidas entre las ciencias y las humanidades, entre las ciencias naturales y las sociales, entre explicar y comprender, entre la verdad científica y las opiniones sobre la realidad. Nos parece un error la separación entre la formación filosófica y la formación en cualquiera de las disciplinas científicas. Al proceso de especialización de los dominios de cada una de ellas, del lado de los "cuantis" o de los "cualis", se van adicionando fobias y filias diferentes, sistemas de clasificación, de identificación y descalificación que en forma de prejuicios acompañan y sazonan la convivencia de las diferentes disciplinas. El resultado es que frente a problemas críticos que no pueden ser estudiados solamente desde una sola o un conjunto de disciplinas, parece imposible entenderse entre sí.

Cada uno hace su parte, pero no se cultiva la capacidad para organizarse frente a graves problemas que solo el conocimiento interdisciplinario puede enfrentar y su pertinencia ha sido fundamentada desde la Epistemología Genética a través de la teoría de los sistemas complejos de Rolando García (2006). 
Invitado a su seminario semanal y a los experimentos clínicos, Piaget opera una demolición del empirismo lógico de Rolando García (que había estudiado con Carnap y Reichenbach) frente a las evidencias que García no puede explicar desde una posición empirista. García se convierte así, estudiando a fondo la EG, en un constructivista tan crítico que le señala al propio Piaget algunas de las zonas "no constructivistas" de su edificio teórico. A partir de ahí y hasta su muerte en 1980, Piaget trabajaría muy estrechamente con García. De forma destacada escriben juntos una obra excepcional que sostiene que los mecanismos constructivos del conocimiento tienen una continuidad funcional en el tiempo y son los mismos que operan tanto en el desarrollo psicogenético de los niños como en la historia de la creación de los conceptos de cada ciencia (Piaget \& García, 1982). Al mismo tiempo, en esa obra explicitan y nombran los mecanismos constructivos de todo proceso de conocimiento en los humanos y es García el que introduce al final de esa obra conjunta, el concepto de Marco Epistémico (Piaget \& García, 1982: 228) con el que muestra que los problemas y las preguntas que condicionan el desarrollo de la ciencia surgen de una toma de posición ideológica, en el mejor de los casos política, frente a los problemas.

No hay tal asepsia de los valores en la ciencia. Un marco epistémico delimita el tipo de preguntas que se pueden hacer en un tiempo determinado, pero no determina el contenido de la ciencia.

Se abre otra forma de entender la objetividad pura y prístina que pregona la ciencia empirista. Y también este concepto nos ayuda a comprender el motor de las llamadas revoluciones científicas, que no depende de un aparato o dispositivo más preciso para las observaciones (el telescopio, el microscopio, etc.), sino del tipo de preguntas que orientan la investigación.

Así aprendemos que la cientificidad de una investigación no depende ni de las técnicas ni de los métodos, sino de las preguntas (González \& Krohling-Peruzzo, 2019: 529). 
La obra El conocimiento en construcción. De las formulaciones de Jean Piaget a la teoría de los sistemas complejos de Rolando García (2000) consolida la maduración de la Epistemología Genética, además de otras de sus aportaciones señaladas, al potenciar el entendimiento del conocimiento entendido como si fuera un sistema complejo.

Rolando García pasó los últimos años de la vida productiva trabajando en México desde 1980 hasta 2012. Cuando en 1980 muere Piaget, García declina tomar la dirección del Centro en Ginebra, regresa con su familia a América Latina, viene a la Ciudad de México invitado por la Universidad Autónoma MetropolitanaXochimilco, y ahí comienza en diferentes regiones de México un trabajo fascinante sobre los sistemas alimentarios y la sociedad, que es la continuación de su estudio sobre la sequía en el Sahel y la catástrofe que cobró cientos de miles de víctimas en África y otras partes del mundo. El sociólogo Pablo González Casanova, lo lleva a la Universidad Nacional Autónoma de México donde pasa sus últimos 14 años productivos. De esa y otras experiencias de investigación es que desarrollará su teoría de sistemas complejos (García, 2006) como una concreción de una teoría general de los procesos de conocimiento.

García llegó a Ginebra y encontró a Piaget siendo un reconocido físico de la atmósfera, un empirista lógico de primera calidad, un gestor universitario que siempre buscó promover la ciencia comprometida con las condiciones de su natal Argentina y de América Latina. Regresa de Europa como un epistemólogo agudo y crítico que colabora y potencia con Piaget la consolidación de esa nueva disciplina de la que hemos hablado más atrás.

Los nombres y las luces de Piaget y de Freire dentro del mundo académico son enormes. Y tanto de uno como de otro se pueden encontrar centenas de versiones, unas más fundamentadas que otras, sobre sus aportaciones a los procesos de conocimiento (Piaget), y a los procesos de alfabetización que desembocan en la concientización de los oprimidos sobre su propia condición, su pasado y su futuro posibles (Freire).

Los avances de la Epistemología Genética son perfectamente compatibles con las formulaciones conceptuales y la práctica que desarrolla Freire en su trabajo como practicante y a la vez teórico de los procesos de alfabetización. 
Incluso, me parece que ayudan a comprender mejor y más críticamente muchas de las decisiones y estrategias que desarrolla Freire en su práctica pedagógica y algunas que no llegó a desarrollar.

Freire ha sido conocido principalmente como pedagogo activista que lucha, con sus armas, por la justicia y la democracia. Cicilia Krohling-Peruzzo junto con otros autores, lo coloca incluso en los orígenes del desarrollo de la técnica de investigación acción (Krohling-Peruzzo, 2019: 475, en González \& KrohlingPeruzzo, 2019).

Piaget es un científico de tiempo completo, conocido como un pedagogo y psicólogo de niños, que construye una teoría revolucionaria muy potente, pero desapercibida o mal leída, sobre los procesos de construcción de conocimiento. Por eso nos parece que pueden dialogar con provecho ambas perspectivas.

Freire conocía el trabajo de las primeras formulaciones de Piaget, pero nunca se dedicó a trabajar a fondo esa veta, ni desarrollar una perspectiva científica propia. No era su campo. Las condiciones sociohistóricas en las que vivió marcaron los límites de lo posible y de lo probable en su trabajo. Con Piaget sucede lo mismo. Probablemente conocía de lejos algo de la obra de Freire, pero su pasión y obsesión por crear una teoría robusta que terminara con las mistificaciones empiristas e innatistas sobre el conocimiento, no le dejó mucho tiempo para otras cosas. Un año antes de la muerte de Piaget, en 1979, la Universidad de Ginebra le otorgó a Paulo Freire un Doctorado Honoris Causa, el único autor latinoamericano que se incluye en una lista de los 10 pedagogos más importantes del mundo. Ahí se vieron ambos pensadores. Al término de esa ceremonia Piaget antes de salir del edificio, se detiene, felicita a Freire y se marcha, como refiere Becker (2017: 32). No hubo tiempo para más.

El trabajo de Freire está plenamente soportado por una teoría científica rigurosa que fundamentalos principios básicos del funcionamiento exitoso de su pedagogía². Fértiles y poco explorados esos improbables caminos.

\footnotetext{
2. Digresión convivial: si Jean Piaget y Paulo Freire se reunieran improbablemente en una pequeña fiesta casera, para celebrar la vida, comer, beber y cantar (algo que me parece fuera de la experiencia del suizo, pero más próxima a la experiencia del nordestino), tal vez cantarían a dos voces una versión igualmente improbable y adaptada del bolero "Nos hizo falta tiempo" https://www.youtube.com/watch?v=Uc8wvU7hmcQ
} 


\section{Conclusiones y exploración de algunos senderos que se bifurcan}

Entre 1982 y 1986 participé en algunos seminarios que Rolando García impartió en la universidad y en reuniones mensuales como asesor metodológico de mi tesis doctoral. Al entrar a la UNAM nos colocaron en el programa que él dirigía. Retomamos entonces el trabajo y en la revisión profunda de su texto El conocimiento en construcción (García, 2000) y se planteó una pregunta. "Si los mecanismos constructivos para conocer/actuando sobre el mundo nunca detienen su movimiento dialéctico ¿qué lugar tiene en la Epistemología Genética el estudio del desarrollo de aquellas personas que, si bien ya han construido y elaboran abstracciones reflexivas e inferencias complejas para actuar diestramente en su mundo, nunca llegarán a volverse científicos? Esa es la enorme mayoría de la población".

Rolando pensó un poco y nos dijo, palabras más, palabras menos: "Piaget se concentró en los niños, porque en esas edades la fuerza de la creación, estructuración y desestructuración de los conocimientos es enorme y permite estudiar esos mecanismos comunes a todas y todos, de una forma más clara. En el mundo social adulto, una vez que se configuran las estructuras más complejas, el potencial creativo desciende. Hay menos construcción de conocimiento que desarrollo del mismo y Piaget no estaba en posibilidad de dedicarle tiempo y recursos a esa veta".

Conocer, es aprender a diferenciar aquello que antes nuestra estructura no diferenciaba y a integrar esas diferencias que antes no integrábamos dentro de estructuras superiores que nos habilitan para actuar de otra forma en nuestra realidad. Si no diferenciamos e integramos bien, tampoco actuaremos inteligentemente.

En México y América Latina (y en todas las sociedades que han sido "globalizadas" desde afuera y a la fuerza, así llamadas "periféricas" o más recientemente nombradas como "sur global"), existen vastísimos contingentes de hombres y mujeres históricamente empobrecidos y miserabilizados, no solo en la producción económica, sino en el mundo simbólico. A fuerza de siglos, han desarrollado una autopercepción heterodeterminada, definida desde afuera, exógenamente por otros 
(González, 2019: 99), que Freire llama "opresores". El entramado de relaciones simbólicas en que se tejen percepciones es uno de los nodos interconectados de la relación hegemonía-subalternidad. Esos adultos, a pesar de tener, según establece la Epistemología Genética, todo el potencial reflexivo ya construido biopsico-socialmente en su accionar práctico sobre el mundo, todavía no alcanzan a diferenciar e integrar muy claramente los componentes, las relaciones y las transformaciones de su ser social en devenir, en movimiento, en proceso. Muchos tampoco se han logrado apropiar del poderoso artefacto cultural que constituye la tecnología de la lectoescritura (Ferreiro, 2007).

Otros más, a pesar de ya haber sido "alfabetizados", no parecen aprovechar esa capacidad para "leer y escribir" su palabra, su voz, su versión y su visión en la sociedad que los ha colocado en donde están. Esta condición, no hay que argumentar demasiado, es completamente funcional al injusto orden de las cosas, pero en congruencia con todo el desarrollo de las ideas de la Epistemología Genética, estamos seguros de que podría cambiarse. Si pudiéramos preguntar a Rolando García si eso es posible, respondería enfáticamente: "Eso no es posible. Hay que construir lo posible".

Si usamos las ideas de Freire (2005), para describir lo que él llama "niveles de conciencia" de los oprimidos, la pregunta epistemológica sería, ¿cómo se pasa de un nivel de conciencia a otro? ¿Qué es lo que cambia, qué es lo que se modifica, qué se conserva intacto y qué es lo nuevo que aparece? Una conciencia que opera en modo intransitivo (poco diferenciante de su ser social), "impermeable a desafíos situados fuera de la órbita vegetativa”, (Freire, 2005: 60), plena de supersticiones y naturalizaciones de los procesos sociales, inhábil para organizarse con otros para mejorar sus condiciones, centrada sobre sí misma y sumergida en una cultura del silencio, depresiva y con dificultades para identificar y comunicar sus emociones.

En fin, el método de Freire intenta ayudar a cambiar una condición cultural y social en la que la gente no se da cuenta de que no se da cuenta. El cambio de ahí hacia una conciencia inicialmente transitiva implica que ya se tiene construida alguna 
capacidad para ir y actuar más allá de lo inmediato y por tanto capaz de generar organización básica para presionar hacia cambios sociales y políticos colectivos que les sean favorables.

De esa segunda forma de conciencia, pasar a una conciencia transitiva y crítica quiere decir volverse capaz de integrar diferencias antes desapercibidas que habilitan para construir interpretaciones más profundas, más densas sobre los problemas que les aquejan y de los que logra generar una representación diferenciada de sus causas concretas.

Lo que Freire describe de forma filosófica y metafórica, a partir de su reflexión sobre las experiencias de concientización con centenas de hombres y mujeres de diversas partes del mundo, que en su perspectiva define como "oprimidos", merecería un trabajo riguroso de sistematización y un probablemente un proceso de homologación conceptual con la ciencia de Piaget y García. Al organizarse para construir el conocimiento de su ser social, se inician procesos de empoderamiento de los sujetos. Especialmente aquellos que han sido históricamente "diseñados" $\mathrm{y}$ tratados como meros objetos de estudio y no como sujetos activos del conocimiento. Esa es una de las consecuencias más importantes del legado de Paulo Freire, no solo en Brasil, sino en el mundo. Pero ¿qué significa convertirse en "sujetos de conocimiento"? Los actores sociales que pueden enfrentar sus problemas por medio de la construcción de sus propios conocimientos, ¿realmente se empoderan?

La teoría y los hallazgos de la Epistemología Genética nos dan una poderosa herramienta científica, conceptual y procedimental pertinente para el análisis experiencias de "concientización" como procesos de empoderamiento.

Observar, registrar, identificar, analizar y dialogar colectivamente sobre la especificidad de su inserción en el mundo de la producción de valor, de la organización social, de las representaciones, tradiciones y símbolos es una tarea cotidiana que permite reorganizar y rediseñar nuestras ecologías simbólicas (González, 2019). 
El método de Freire para la alfabetización de adultos puede ser interpretado y fundamentado bajo la luz de una interpretación científica (es decir, histórica, dialéctica, abierta y documentada) de los procesos de construcción del conocimiento. Cualquier teoría científica prueba su potencia cuanto más genera preguntas que la fuerzan a avanzar y explorar zonas que no había cubierto antes o que solo detectó parcialmente.

Al final de aquella conversación con Rolando García en nuestra oficina de la universidad, le dije: "Precisamente, el trabajo de desarrollo de cibercultur@, se ocupa de investigar y promover el desarrollo de las capacidades para conocer el mundo, actuando, no solo sobre la situación específica que causa lo que la gente vive e identifica como un "problema", sino sobre la forma simbólica y práctica de acercarse a ello y de hacer posible la capacidad de transformar sus ecologías simbólicas:

Con la noción de "ecologías simbólicas" designamos el conjunto total de relaciones de sentido que en una sociedad se construyen en la historia con un entorno físico, biológico, psicológico, social y cultural a través de la actividad cognitiva y sus dimensiones más complejas, como la mente, el discurso y la actividad modeladora y adaptativa de las identidades y alteridades de los diferentes y variados colectivos sociales. (González, 2019: 209)

Conceptualmente, la información (I), la comunicación (C) y el conocimiento (@) son tres componentes claves para el desarrollo, la deriva y el entendimiento de tales ecologías simbólicas. Entre estos tres componentes se urde un conjunto de relaciones de interdefinibilidad, de tal manera que la especificidad de las propiedades y características de cada una, dependen de su relación con las otras dos.

Al estudiar y practicar la Comunicación para el Desarrollo, afirmo que la Información, la Comunicación y el Conocimiento deben tomarse como un proceso crucial y no separable que incluye simultáneamente transformaciones biológicas, conductuales y sociales, especialmente aquellas que se han creado colectivamente. Estas transformaciones mejoran tanto la capacidad individual como la grupal 
para diferenciar e integrar (es decir, "conocer") en la acción sus experiencias del mundo, y al hacerlo, potenciar su capacidad de actuar, confrontar y superar sus condiciones y contradicciones sociales.

Cuando un grupo determinado de personas que sufre y padece problemas críticos en su vida cotidiana (hambre, huracanes, maremotos, violencia familiar, inseguridad social, precariedad y explotación laboral, depresión, malnutrición, pandemias, discriminación, etc.) al comenzar a "cultivar" y construir su propio conocimiento, comienza a "concientizarse", ese grupo activa un proceso de empoderamiento que, en términos breves, significa que ese colectivo recupera históricamente su capacidad para hacer y modificar el mundo de su vida. Tanto en lo material, como en lo simbólico. Uno de lo que podemos llamar "indicadores" de que el proceso de reconstrucción de sus sistemas de IC@, del trabajo sobre sus concepciones y sus procesos, es que recuperan o conquistan la capacidad para narrarse a sí mismos y dirigir su acción colectiva contra sus problemas críticos.

Esa capacidad para narrarse es recuperada, se objetiva en el aumento de su capacidad de elaborar un discurso coherente y propio sobre el pasado, en el mejoramiento de su pericia y oportunidad para generar sus propias definiciones, tan sensibles como bien documentadas, de la situación presente y el aumento en la voluntad para abrir los futuros con diversos mundos posibles. La lucha por desocupar sus territorios simbólicos que han sido y permanecen ocupados pasa necesariamente por el rediseño de su relación simbólica tridimensional: a) con la información, entendida no como "las noticias", sino como la capacidad de establecer relaciones entre cosas, eventos, y personas con signos y textos cada vez más complejos que se vuelven significativas, donde antes no podían hacerlo; b) con la comunicación, entendida, no como enviar mensajes y recibirlos, sino como la capacidad de coordinar acciones con otros, es decir, de autoorganizarse; y c) con el conocimiento, esa forma de asimilar y acomodar el mundo que nos transforma al mismo tiempo que lo transformamos mediante la diferenciación y la integración, como el producto de abstracciones reflexivas que habilitan al grupo, al colectivo con mejores grados de autodeterminación e inteligencia. 
La Epistemología Genética, ha desarrollado la teoría científica rigurosa y pertinente para comprender estos procesos. La Pedagogía de Freire, justo trabaja con aquellos que no estuvieron incluidos en la historia de consolidación de la Epistemología Genética.

La investigación y desarrollo de cibercultur@, es decir, de la capacidad de autodeterminación que se puede cultivar y desarrollar con los procesos de conocimiento, potenciada por la organización e inteligencia colectiva, es el reto que desde hace un par de décadas comenzamos a enfrentar, tratando de ver un poco más lejos, montados en los hombros de gigantes.

Sin embargo, esto que deseamos, no es posible. Tendremos que construir lo posible. 


\section{Bibliografía}

- BECKER, F. (2017). Paulo Freire e Jean Piaget: Teoria e prática, en Schème. Revista Eletrônica de Psicologia e Epistemologia Genéticas, 9(Número Especial), 7-47.

- BOFF, L. (2014). Saber cuidar. Ética do humano - compaixão pela terra. Petrópolis: Vozes.

- BUNGE, M. (1983). La investigación científica. México: Ariel.

- CALDART, R. (2004). Pedagogia do Movimento Sem Terra. São Paulo: Expressão Popular.

- DALE, J. \& HYSLOP-MARGISON, E. (2010). Paulo Freire: Teaching for Freedom and Transformation. The Philosophical Influences on the Work of Paulo Freire, Heidelberg. New York \& London: Springer.

- DUSSEL, E. (1998). Ética de la liberación en la edad de la globalización y de la exclusión, Madrid: Trotta.

- FERREIRO, E. (2007). Alfabetización de niñosy adultos. Textos escogidos. México: CREFAL.

- FREIRE, P. (1973). La educación como práctica de la libertad. México: Siglo XXI.

- FREIRE, P. (1993). Pedagogía de la esperanza. México: Siglo XXI.

- FREIRE, P. (2005). Pedagogía del oprimido. México: Siglo XXI. 55a Edición, Nuevo formato.

- FREIRE, P. (2010). Pedagogia da autonomia. Saberes necessários à prática educativa. São Paulo: Paz e Terra.

- GARCÍA, R. (2000). El conocimiento en construcción. De las formulaciones de Jean Piaget a la teoría de sistemas complejos. Barcelona: Gedisa.

- GARCÍA, R. (2006). Sistemas complejos. Conceptos, método y fundamentación epistemológica de la investigación interdisciplinaria. Barcelona: Gedisa. 
- GARCÍA, R. (2008). Dialéctica, psicogénesis e historia de las ciencias. En J. PIAGET. Las formas elementales de la dialéctica (201-216). Barcelona: Gedisa.

- GONZÁlEZ, J. A. (Ed.) (2018). No está muerto quien pelea. Homenaje a la obra de Rolando García Boutigue. Recuperado de https://cutt.ly/igehsDu

- GONZÁLEZ, J. A. (2019). Entre cultura(s) y cibercultur@(s). Incursiones y otros derroteros no lineales, 3 a . Edición. Recuperado de https://cutt.ly/xgehdUh

- GONZÁlEZ, J. A. \& KROHLing-PERUZZO, C. (Eds.) (2019). Arte y oficio de la investigación científica. Cuestiones epistemológicas y metodológicas. Recuperado de https://cutt.ly/Kgehf2d

- KROHLING-PERUZZO, C. \& GONZÁLEZ, J. A. (2018). Agroecología y antroponomía en movimientos sociales de Brasil. INTERdisciplina, 6(14), 205235. Recuperado de https://cutt.ly/Sgehgbq

- OLIVEIRA, P. \& DE CARVALHO, P. (2007). A intencionalidade da consciência no processo educativo segundo Paulo Freire. Paidéia, 17(37), 219-230.

- PIAGET, J. (1973). La formación del símbolo en el niño. México: Fondo de Cultura Económica.

- PIAGET, J. \& GARCÍA, R. (1982). Psicogénesis e historia de la ciencia. México: Siglo XXI.

- VYGOTSKI, L. \& LURIA, A. (2007). El instrumento y el signo en el desarrollo de niño. Madrid: Fundación Infancia y Aprendizaje. Edición a cargo de Pablo del Río y Amelia Álvarez. 


\section{Biografía}

\section{Jorge A. González}

CEIICH-UNAM (México)

ORCID: 0000-0001-7844-9260

jorge.labcomplex@gmail.com

Investigador a tiempo completo del Centro de Investigaciones Interdisciplinarias en Ciencias y Humanidades de la Universidad Nacional Autónoma de México (CEIICH-UNAM). Estudia la dimensión simbólica de la alimentación desde la teoría de los sistemas complejos. Investiga y desarrolla comunidades emergentes de conocimiento. Su libro más reciente (con Cicilia Krohling Peruzzo): Arte y oficio de la investigación científica. Cuestiones epistemológicas y metodológicas, Quito, Ciespal, 2020. 